\title{
Hepatitis in Dengue Shock Syndrome
}

Luiz José de Souza, Helder Gonçalves Carneiro, João Tadeu Damian Souto Filho, Thiago Ferreira de Souza, Vitor Azevedo Côrtes, Carlos Gicovate Neto, Diogo Assed Bastos and Edno Wallace da Silva Siqueira
Campos Faculty of Medicine, Lílian Neves Clinic, Reference Center for Dengue, Hospital dos Plantadores de Cana, Campos dos Goytacazes, RJ, Brazil

\begin{abstract}
Dengue fever is the most frequent arbovirus disease in the world and the most important one in terms of morbidity and mortality. Atypical manifestations of dengue have become commonplace during the last few years, including hepatic damage, which manifests mainly by pain in the right hypochondrium and an increase in the levels of aminotransferases. We describe a case of acute hepatitis in a patient with Dengue Shock Syndrome Grade III. We analyzed the clinical and laboratory aspects of this atypical complication of dengue as well as the differential diagnoses.

Key Words: Acute hepatitis, dengue, dengue hemorrhagic fever.
\end{abstract}

Dengue is an acute infectious disease caused by an arbovirus of the flavivirus genus, and is transmitted by the female of the mosquitoes Aedes aegypti, A. albopictus, A. scutellaris and A. polynesiensis. The classical form of dengue is an acute and self-limited disease characterized by fever, prostration, headaches, retro-orbital pain, myalgia, nausea, vomiting, skin rash, leukopenia and thrombocytopenia [1-3].

Dengue is in some cases associated with alterations of hepatic functions and typical manifestations of acute hepatitis, such as pain localized in the right hypochondrium, hepatomegalia, jaundice and elevations in the levels of aminotransferases. In the case of hepatitis, the levels of aminotransferases reach their peak on the ninth day after the appearance of symptoms and go back to normal levels within three weeks. Though the liver is not the main target organ of this disease, there are cases where histopathological

Received on 17 July 2002; revised 25 October 2002.

Address for correspondence: Dr. Luiz José de Souza. Sociedade Brasileira de Clínica Médica - Regional Rio de Janeiro. Av. Alberto Torres, 217 - Centro. Zip code: 28035-580, Campos dos Goytacazes - RJ. Phone/Fax: (22) 2723-9243.

E-mail:sbcm.rol@terra.com.br

The Brazilian Journal of Infectious Diseases 2002;6(6):322-327 (C) 2002 by The Brazilian Journal of Infectious Diseases and Contexto Publishing. All rights reserved. 1413-8670 findings, including centrotubular necrosis, fatty alterations, Kupffer cells hyperplasia, acidophilic bodies and monocytic infiltrates of the portal tract, have been detected in patients with Dengue Hemorrhagic Fever (DHF) and Dengue Shock Syndrome (DSS). The viral disease is self-limited but hepatic insufficiency can occur in some patients [4-7].

We report a case of acute hepatitis in a patient with DSS Grade III.

\section{Case Report}

LPC, male, 9 years old, white, from Campos dos Goytacazes, RJ, resident in an urban area and without any history of a recent trip to other regions.

The patient started presenting clinical manifestations of high grade fever $\left(103.1^{\circ} \mathrm{F}\right)$, myalgia, headache, retro-orbital pain and progression to nausea and vomiting. He sought medical treatment and was hospitalized. Upon hospital admission, the patient had a fair general condition and was adequately hydrated, red-faced, acyanotic, anicteric, feverish $\left(102.0^{\circ} \mathrm{F}\right)$ and eupneic. The respiratory tract (RT), (CVT) cardiovascular tract and abdomen had no major alterations. (BP) Arterial Blood Pressure was $120 \mathrm{x}$ $80 \mathrm{mmHg}$, Heart Rate (HR) 96 beats/min;the lower limbs were free of edema. The patient received symptomatic medication (dipyrone and 
metoclopramide) and evolved with clinical amelioration. He was discharged from the hospital two days later for an outpatient follow-up.

On the fourth day after the outset of symptoms the patient went back to the hospital, presenting an expressive worsening of his general condition, agitation, dehydration $(++/ 4)$, fever $\left(100,4^{\circ} \mathrm{F}\right)$, centrifuge morbilliform exantemas, slightly dyspneic, clear lung auscultation, CVT : normal cardiac auscultation, $\mathrm{BP}=100 \times 60 \mathrm{mmHg}, \mathrm{HR}=108$ beats/min, normal pulse, flaccid and depressible abdomen that was painful upon palpation of the upper portion, painful hepatomegalia and splenomegaly. He had a positive Tourniquet Test (TT). The patient was hospitalized and laboratory exams at admission showed the following values: $(\mathrm{Ht})$ hematocrit $=40.3 \%$; $(\mathrm{Hb})$ hemoglobin $=14.3$ $\mathrm{g} / \mathrm{dL}$; leukocytes $=3,400 / \mathrm{mm}^{3}$ (three atypical lymphocytes); platelets $=31,000 / \mathrm{mm}^{3} ; \mathrm{PT}$ (Prothrombin Time)/PA (Prothrombin Activity)=16 sec./64\%; PTT (Partial Thromboplastin Time) $=1 \mathrm{~min} .01 \mathrm{sec}$; INR (International Normalized Ratio) $=1.55$; $(\mathrm{AST}$ or SGOT) Aspartate aminotransferase $=235 \mathrm{U} / \mathrm{L}$; (ALT or SGPT) alanine aminotransferase $=199 \mathrm{U} / \mathrm{L}$; urea $=25 \mathrm{mg} / \mathrm{dL}$; creatinine $=0.5 \mathrm{mg} / \mathrm{dL}$; (UA, Urinalysis) abnormal elements and analysis of sediment indicated a urine density of 1,025 without any other abnormalities.

On the fifth day of the disease the patient was diaphoretic, torporous, anemic $(+/ 4+)$, feverish, icteric $(++/ 4+)$ and dyspneic. Respiratory Tract: dull sound on pulmonary percussion associated with disappearance of vocal fremitus and vesicular murmur in the lower half of the right hemithorax and base of the left hemithorax. BP (blood pressure $)=60 \mathrm{mmHg} x$ $40 \mathrm{mmHg}$, tachycardiac (140 beats/min), filiform pulse, delayed capillary filling, distended abdomen, painful abdomen on palpation of the epigastrium and right hypochondrium; the liver was palpable $9 \mathrm{~cm}$ below the right costal margin and had a firm consistence and a smooth surface; the spleen was palpable $6 \mathrm{~cm}$ below the left costal border; peristalsis was present, lower limbs with no abnormalities, positive TT (Tourniquet Test). Laboratory tests: $\mathrm{Ht}=42.2 \%$; $\mathrm{Hb}=15.4 \mathrm{~g} / \mathrm{dL}$; platelets $=34,000 / \mathrm{mm}^{3}$; total proteins $=5.3 \mathrm{~g} / \mathrm{dL}$, albumin $=2.6 \mathrm{~g} / \mathrm{dL}$, globulin $=2.7 \mathrm{~g} /$ $\mathrm{dL}$; (TB) total bilirubin=3.1 $\mathrm{mg} / \mathrm{dL},(\mathrm{DB})$ direct bilirubin $=2.7 \mathrm{mg} / \mathrm{dL}$, (IB) indirect bilirubin $=0.4 \mathrm{mg} /$ $\mathrm{dL}$; sodium $=126 \mathrm{mEq} / \mathrm{L}$; potassium $=4.1 \mathrm{mEq} / \mathrm{L}$; Chest x-ray: pleural effusion (Figure 1); total abdominal ultrasound: hepatosplenomegaly (Figure 2), free fluid in the Morrison space (Figure 3), posterior cul-de-sac was empty in a supine position; moderate amount of bilateral pleural effusion (greater on the right side). Serological diagnosis for dengue (third-generation ELISA IgM reactive and IgG non-reactive; Serological tests for hepatitis A (Anti-HAV IgM-ELISA) negative; Serological tests for hepatitis B: Hbs Ag and Anti Hbc were negative; $\mathrm{PCR}$ for Hepatitis $\mathrm{C}$ was negative.

On the sixth day after onset of symptoms, the patient progressed with a worsening of jaundice $(+++/ 4)$ and hemodynamic stabilization. The patient presented dark urine, melena and two episodes of epistaxis, which ceased spontaneously. Laboratory exams revealed: $\mathrm{Ht}=38.3 \%, \mathrm{Hb}=13.4 \mathrm{~g} / \mathrm{dL}$, platelets $=47,000 / \mathrm{mm}^{3}$, total proteins $=5.8 \mathrm{~g} / \mathrm{dL}$, albumin $=3.3 \mathrm{~g} / \mathrm{dL}$, globulin=2.5g/dL; TB=9.4mg/dL, DB=7.8mg/dL, $\mathrm{IB}=1.6 \mathrm{mg} / \mathrm{dL}$; alkaline phosphatase $(\mathrm{AP})=130 \mathrm{U} / \mathrm{L}$; $\mathrm{AST}=1110 \mathrm{U} / \mathrm{L} ; \mathrm{ALT}=760 \mathrm{U} / \mathrm{L}$; sodium $=131 \mathrm{mEq} / \mathrm{L}$; potassium $=4.2 \mathrm{mEq} / \mathrm{L} ; \quad$ urea $=17 \mathrm{mg} / \mathrm{dL}$ and creatinine $=0.4 \mathrm{mg} / \mathrm{dL}$.

On the eighth day, the patient showed an improvement of his clinical condition, with remission of jaundice, progressive reduction of hepatosplenomegaly and negative TT. Laboratory findings: $\mathrm{Ht}=35.7 \% ; \mathrm{H}$ $=12.5 \mathrm{~g} / \mathrm{dL} ;$ leukocytes $=6,000 / \mathrm{mm}^{3} ;$ platelets $=208,000 /$ $\mathrm{mm}^{3} ;$ total proteins $=6.9 \mathrm{~g} / \mathrm{dL}$, albumin $=4.3 \mathrm{~g} / \mathrm{dL}$, globulin=2.6g/dL; TB=5.4mg/dL, DB=4.3mg/dL, $\mathrm{IB}=1.1 \mathrm{mg} / \mathrm{dL} ; \mathrm{AP}=273 \mathrm{U} / \mathrm{L} ; \mathrm{AST}=120 \mathrm{U} / \mathrm{L}$; $\mathrm{ALT}=225 \mathrm{U} / \mathrm{L}$; urea $=18 \mathrm{mg} / \mathrm{dL}$; creatinine $=0.8 \mathrm{mg} / \mathrm{dL}$; Ultrasound: hepatosplenomegaly, absence of free fluid in the cavity and absence of pleural effusion.

A diagnosis of hepatitis associated with Dengue Shock Syndrome (DSS) was made based on the clinical condition and laboratory findings. The patient was released from the hospital and was instructed to return to the outpatient clinic for a follow-up treatment.

Serology for yellow fever (IgM) and seroagglutination for Leptospirosis yielded negative 
Table 1. Clinical and laboratory findings observed in a case of Dengue Shock Syndrome

\begin{tabular}{|c|c|c|c|c|c|}
\hline \multirow[t]{2}{*}{ Clinical findings } & \multicolumn{5}{|c|}{ Time since onset dengue } \\
\hline & $4^{\text {th }}$ day & $5^{\text {th }}$ day & $6^{\text {th }}$ day & $8^{\text {th }}$ day & $28^{\text {th }}$ day \\
\hline \multicolumn{6}{|l|}{ Clinical findings } \\
\hline Abdominal pain & Yes & $\operatorname{Yes}(\uparrow)$ & No & No & No \\
\hline Jaundice & No & $++/ 4$ & $+++/ 4$ & No & No \\
\hline Mucosal discoloration & $+/ 4$ & $+/ 4$ & No & No & No \\
\hline $\begin{array}{l}\text { Liver (cm below right } \\
\text { costal margin) }\end{array}$ & 4 & 9 & 9 & 6 & 0 \\
\hline $\begin{array}{l}\text { Spleen (cm below left } \\
\text { costal margin) }\end{array}$ & 2 & 6 & 6 & 3 & 0 \\
\hline Pleural effusion & No & Yes $(\uparrow \mathrm{D})$ & Yes $(\uparrow D)$ & No & No \\
\hline Ascites & No & Yes & Yes & No & No \\
\hline Hypotension & Yes & $\operatorname{Yes}(\uparrow)$ & No & No & No \\
\hline \multicolumn{6}{|l|}{ Laboratory findings } \\
\hline Tourniquet test & + & ++ & ++ & Negative & Negative \\
\hline Hematocrit $(\%)$ & 40.3 & 42.2 & 36.3 & 35.7 & 36 \\
\hline Hemoglobin (g/dL) & 14.3 & 15.4 & 13.4 & 12.5 & 11.2 \\
\hline Platelets $\left(\mathrm{mm}^{3}\right)$ & 31,000 & 34,000 & 47,000 & 208,000 & 260,000 \\
\hline $\operatorname{AST}(\mathrm{U} / \mathrm{l})$ & 235 & 1,200 & 1,110 & 120 & 38 \\
\hline $\operatorname{ALT}(\mathrm{U} / \mathrm{l})$ & 199 & 940 & 760 & 225 & 35 \\
\hline \multicolumn{6}{|l|}{ Imaging Exams } \\
\hline Chest x-ray & Nornal & Effusion $^{\mathrm{a}}$ & Effusion $^{\mathrm{a}}$ & Normal & Normal \\
\hline Abdominal ultra-sound & Normal & Abnormal $^{\mathrm{b}}$ & Abnormal $^{\mathrm{b}}$ & Abnormal $^{\mathrm{c}}$ & Normal \\
\hline
\end{tabular}

(a) bilateral, greater on the right; (b) hepatosplenomegaly and low-volume ascites; (c) exclusively hepatosplenomegaly.

Figure 1. Posteroanterior chest $x$-ray showing pleural effusion 
Figure 2. Abdominal Ultrasound showing hepatosplenomegaly

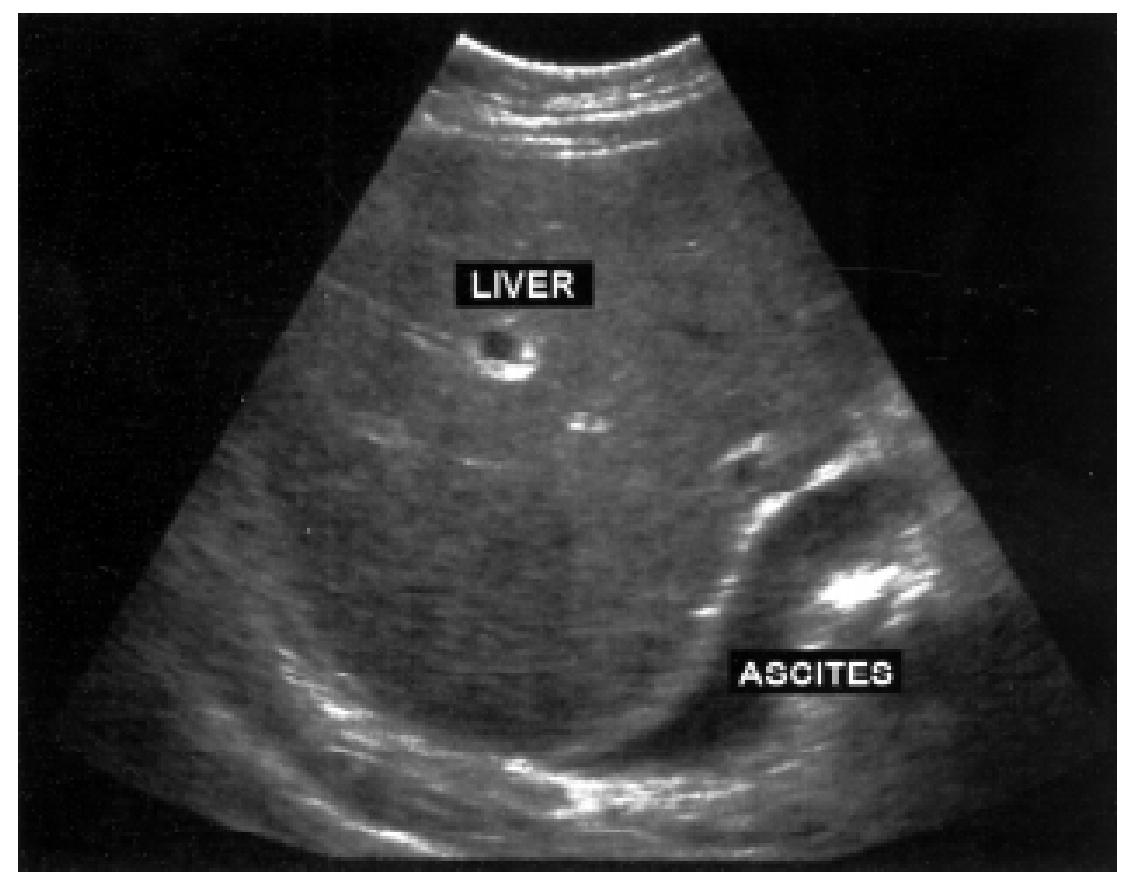

Figure 3. Abdominal Ultrasound showing ascites

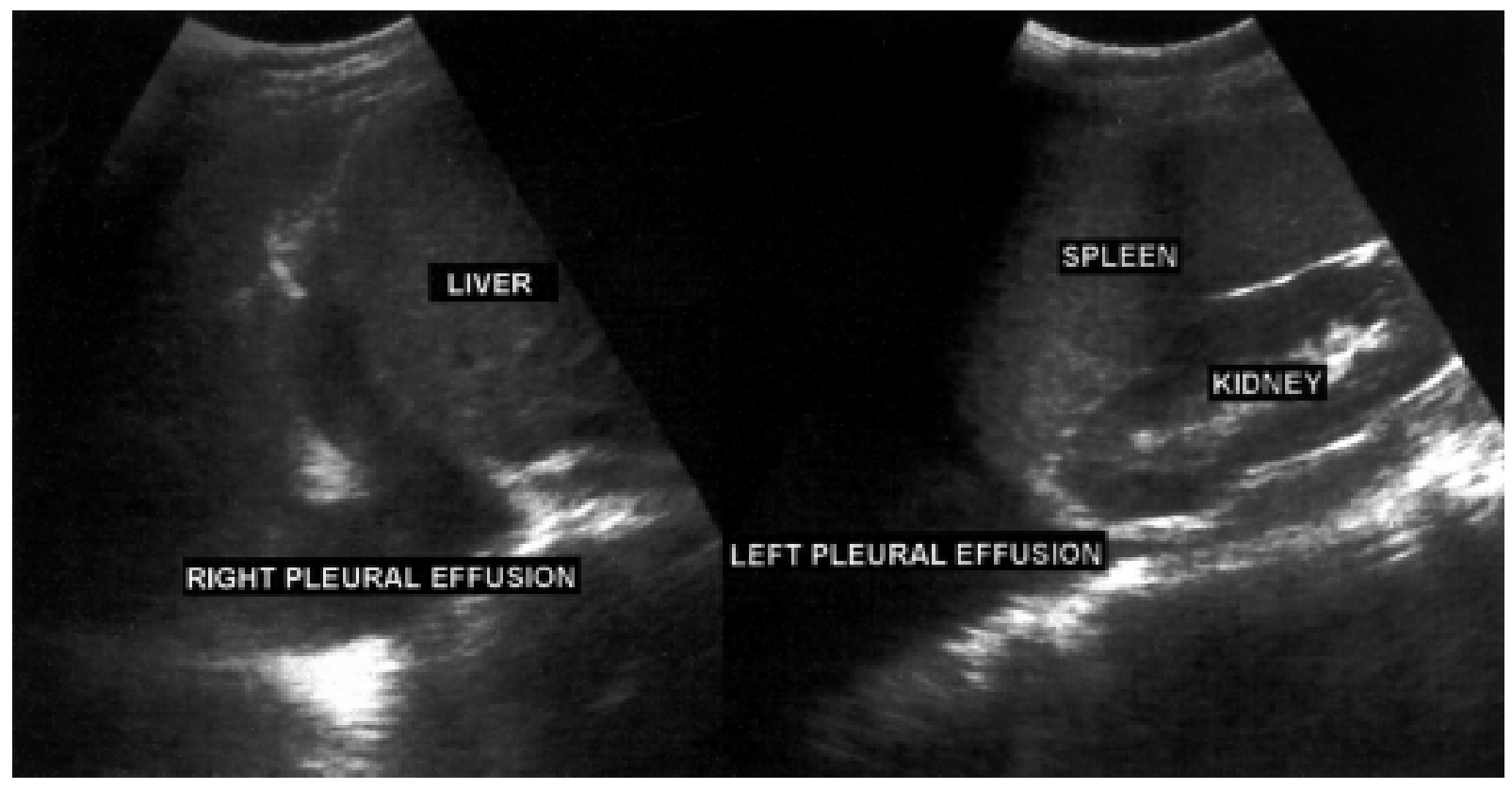


results. Polymerase Chain Reaction (PCR) identified serotype 3 of dengue virus.

During outpatient follow-up, the patient presented an improvement of his clinical condition and laboratory findings, including normalization of aminotransferases levels and remission of hepatosplenomegaly 28 days after the onset of the disease.

\section{Discussion}

Dengue has become a serious public health problem in the last couple of years; it has attracted the attention of health authorities in Brazil [1,3]. From 1982 to 1998, $1,672,883$ cases of dengue were identified in the country. In the first quarter of 2001 alone, 9,886 cases were notified in Rio de Janeiro state [1].

Dengue Hemorrhagic Fever (DHF), according to the World Health Organization (WHO), is a febrile disease caused by one of the serotypes of the dengue virus and is characterized by a tendency for bleeding and an increase in vascular permeability that can lead to shock [8].

Thrombocytopenia and the increase of vascular permeability are responsible, respectively, for the hemorrhagic phenomena and the vascular extravasation of fluids, electrolytes, proteins and cells, which can lead to cavity effusions [1-3].

The clinical picture of classic dengue begins with a high grade fever, intense headache and myalgia, prostration, nausea, vomiting and arthralgia. The first clinical manifestations of DHF are indistinguishable from those of classic dengue.

By the third day after the onset of the disease, the patient may present leukopenia, thrombocytopenia $\left(<100,000 / \mathrm{mm}^{3}\right)^{*}$ and hemoconcentration (hematocrit increase of $20 \%$ or more of normal value)**. Epigastralgia, pain in upper right quadrant and generalized abdominal pain are frequent symptoms. The hemorrhagic manifestations can be absent or on the contrary can dominate the clinical picture, including petechiae, ecchymoses, purpura, epistaxis, gingival bleeding, gastrointestinal hemorrhage and hematuria. The occurrence of polyserositis is also possible and this condition presents as pleural effusion, mainly on the right side, ascites and pericardial effusion. There are four recognized grades defined according to the level of seriousness: Grade I: thrombocytopenia*, hemoconcentration**, positive TT (Tourniquet Test) and absence of spontaneous bleeding; Grade II: thrombocytopenia*, hemoconcentration**, positive TT and presence of spontaneous bleeding; Grade III: thrombocytopenia*, hemoconcentration**, positive TT and circulatory insufficiency (filiform pulse, drop of 20 $\mathrm{mm} \mathrm{Hg}$ or greater in arterial blood pressure, cold extremities and apprehension); Grade IV: thrombocytopenia*, hemoconcentration**, positive TT, declared shock with zero level of arterial blood pressure and impalpable pulse [1,2,8].

The differential diagnosis of DSS includes meningococcemia, sepsis caused by Haemophylus influenzae in infants and preschoolers, hemorrhagic viruses such as yellow fever and hematological diseases such as purpura and leukosis. In cases of acute hepatitis, caused by the dengue virus, the differential diagnosis must include leptospirosis, yellow fever, malaria and hepatitis A, B, and C [1,2,8]. In certain individuals the clinical presentation of dengue can assume atypical forms, such as encephalitides (Reye Syndrome), aseptic meningitides, polyneuropathies, acalculous cholecystitis, polyserositis and acute viral hepatitis $[1,2,9]$.

The liver is one of the target organs of dengue and the clinical manifestations of hepatic dysfunction can occur during the course of the disease; more serious disturbances can occur in DHF and DSS [4]. The levels of aminotransferases generally reach maximum values around the ninth day after the first episode of fever and gradually taper off toward normality within two weeks. The disease is self-limiting, but some patients may present hepatic failure [7]. The use of paracetamol can lead to hepatic damage and trigger or worsen the primary lesion caused by the dengue virus and therefore is not indicated in these cases.

Hepatomegaly is the most frequent sign found in DSS, with values ranging from $30 \%$ to $79 \%[4,6]$.

The elevation in the level of AST enzyme is normally greater than the elevation in the level of ALT in dengue patients during the first week of infection, and this is an 
uncommon phenomenon in patients with hepatitis A, $\mathrm{B}$, or C. The release of AST from damaged myocytes may be the mechanism responsible for this occurrence [7]. The levels of these enzymes increase around the third day after the onset of the disease; they reach a peak on the seventh or eighth day and decrease to normal values within three to eight weeks [4].

The presence of jaundice in these cases is apparently multifactorial; it can be due to the hepatic aggression caused by the dengue virus and/or hypoxia and tissue ischemia in cases of shock. In patients with HSS (Hemorrhagic Shock Syndrome) we can find jaundice in from $12 \%$ to $62 \%$ of the cases $[4,6]$.

In this patient the diagnosis of dengue was confirmed according to the criteria indicated by CDC (Centers for Disease Control and Prevention) and hepatic involvement was established by the appearance of jaundice and high levels of aminotransferases and bilirubins [9]. Viral hepatitis A, B and C as well as leptospirosis and yellow fever were ruled out based on laboratory findings.

\section{Acknowledgments}

To collaborators Rita Maria Nogueira (Department of Virology of "Instituto Oswaldo Cruz") and Carlos Bacelar da Silva (“Laboratório Plínio Bacelar”).

\section{References}

1. Nogueira S.A. Dengue: artigo de revisão. Revista de Pediatria Soperj 2001;2(1):22-8.

2. Souza L.J., Ronaldo C., Lopes A.C., et al. Aspectos clínicos da dengue: novos conceitos. Revista Brasileira de Clínica e Terapêutica 2002;28(2):46-52.

3. Ronald C., Souza L.J., Lopes A.C. Revista Brasileira de Clínica e Terapêutica 2001;27(4):168-175.

4. Mohan B., Patwari A.K., Anand V.K., et al. Hepatic Dysfunction in Childhood Dengue Infection. Journal of Tropical Pediatrics 2000;46:40-3.

5. Nguyen T.L., Nguyen T.H., Tieu N.T. The impact of dengue haemorrhagic fever on liver function. Res Virol 1997; 148:273-7.

6. Wahid S.F.S.A., Sanusi S., Zawawi S., et al. A comparison of the pattern of liver involvement in dengue hemorrhagic fever with classic dengue Fever. Southeast Asian J Trop Med Public Health 2000;31(2):259-63.
7. Kuo C.H., Tai D.I., Chang-Chien C.S., et al. Liver biochemical tests and dengue fever. American Society of Tropical Medicine and Hygiene 1992;47(3):265-70.

8. World Health Organization. Dengue hemorrhagic fever: diagnosis, treatment, prevention and control. $2^{\text {nd }}$ edition. Genebra: WHO, p.1-83, 1997.

9. Angibaud G., Luaute J., Laille M., et al. Brain involvement in Dengue fever. Journal of Clinical Neuroscience 2001;8(1):63-5. 